\title{
Analysis of genetic diversity among Indian niger [Guizotia abyssinica ( $L$. f.) Cass.] cultivars based on randomly amplified polymorphic DNA markers
}

\author{
Praveen Nagella \\ Department of Botany \\ Karnatak University \\ Dharwad 580 003, India \\ Tel: 918362771154 \\ Fax: 928362747884 \\ E-mail: npraveen@yahoo.co.in

\section{Niranjana Murthy Hosakatte} \\ Department of Botany \\ Karnatak University \\ Dharwad 580 003, India \\ Tel: 918362771154 \\ Fax: 928362747884 \\ E-mail: nmurthy60@hotmail.com

\section{K.V. Ravishankar} \\ Biotechnology Division \\ Indian Institute of Horticultural Research \\ Hessaraghatta lake Post, Bangalore 580 089, India \\ Tel: 918028466420 \\ Fax: 918028466291 \\ E-mail: ravishankar@iihr.ernet.in
}

\section{Eun-Joo Hahn}

Research Center for the Development of Advanced Horticultural Technology Chungbuk National University

Cheongju 361-763, South Korea

Tel: 82432633245

Fax: 82432725369

E-mail: ejhahn@chungbuk.ac.kr

\section{Kee-Yoeup Paek*}

Research Center for the Development of Advanced Horticultural Technology

Chungbuk National University

Cheongju 361-763, South Korea

Tel: 82432633245

Fax: 82432725369

E-mail: paekky@chungbuk.ac.kr

Financial support: This work is partially supported by Ministry of Education and Human Resources Development; the Ministry of Commerce, Industry and Energy; and the Ministry of Labor, Korean Science and Engineering Foundation, South Korea and Council of Scientific and Industrial Research, New Delhi, India.

Keywords: genetic diversity, Guizotia abyssinica, molecular markers, RAPD.

Abbreviations: PCA: principal component analysis

PCR: polymerase chain reaction

RAPD: randomly amplified polymorphic DNA

Randomly amplified polymorphic DNA (RAPD) markers were used to estimate genetic diversity among 18 cultivars of niger from India. Total genomic DNA was extracted and subjected to RAPD analysis using $\mathbf{8 0}$ arbitrary 10-mer primers; 17 primers were selected, which yielded a total of 124 bands, $41.20 \%$ of them polymorphic. None of the primers produced unique banding pattern for each cultivar. RAPD data were used to calculate a Squared-Euclidean Distance matrix which revealed a minimum genetic distance between

*Corresponding author 
cultivars JNC-6 and $\mathrm{N}-48$ and a maximum distance between IGP-76 and JN-30. Based on the distance matrix, a cluster analysis was done using a minimum variance algorithm. The dendrogram generated, based on Ward's method, grouped 18 niger cultivars into two major clusters. The first cluster consisted of early maturing cultivars (e.g. $\mathrm{N}-129$ and $\mathrm{N}-134 ;$ 80-90 days), and the second of late maturing cultivars (e.g. GA-8 and GA-9; 135-145 days). The present study shows that there is high diversity among the niger cultivars tested and indicates the potential of RAPD markers for identification and maintenance of niger germplasm for crop improvement purposes.

Niger (Guizotia abyssinica (L. f.) Cass. Asteraceae) is an oilseed crop cultivated in Indian subcontinent and East African Countries (Getinet and Sharma, 1996). Niger seeds contain about $40 \%$ edible oil with fatty acid composition of 75-80\% linoleic acid, 7-8\% palmitic and steric acids, and 5$8 \%$ oleic acid (Dutta et al. 1994). The meal remaining after the oil extraction is free from any toxic substances but contains more crude fiber than most oilseed meal. Niger is a completely outcrossing species with self-incompatibility mechanism. Variability exists for morphological characters (Pradhan et al. 1995); however these characters are not discrete and hence complicate the niger improvement programs. Consequently, varieties identification or genetic purity assessment are difficult. Identify, purity and stability of varieties are very important for effective seed quality control programs.

DNA markers provide a powerful tool for genetic evaluation and marker-assisted breeding of crops, and especially for cultivars identification. Among the different types of molecular markers, random amplified polymorphic DNA (RAPD) markers are particularly useful for the assessment of genetic diversity because of their simplicity, speed and relatively low cost (Nybom, 2004). RAPD markers have been used extensively in several crops including cucumber (Horejsi and Staub, 1999), potato (Demeke et al. 1996) and pepper (Prince et al. 1995). The purpose of the present study was to investigate, through the use of RAPD markers, the genetic diversity of selected Indian niger germplasm accessions from different origin and pedigree background. The present study is the first attempt to estimate genetic variability among Indian niger cultivars using RAPD markers.

\section{MATERIALS AND METHODS}

\section{Plant material and DNA extraction}

Seeds of eighteen niger (Guizotia abyssinica (L. f.) Cass.) cultivars (which are all endogamic lines) namely Ootacamund, JNC-6, IGP-76, ONS-124, GA-8, IGPN9629, JNC-1, IGPN-9705, GA-9, IVT-2003-7, N-71, NPJ-
41, IGPN-9628, N-129, JNC-2, N-134, JN-30 and N-48 were obtained from the Project coordinator, All India Coordinated Research Project (AICRP on Sasame and niger), Jawaharlal Nehru Agricultural University Campus, Jabalpur. The seeds of all cultivars were germinated in plastic containers with vermiculite and maintained at $23^{\circ} \mathrm{C}$ in dark. DNA was extracted from leaves collected from 10 days old seedlings, following the cetyltrimethylammonium bromide (CTAB) method. The extracted DNA was diluted to $10 \mathrm{ng} / \mathrm{\mu l}$ and used for polymerase chain reaction (PCR) amplifications.

\section{RAPD analysis}

A set of 80 random decamer primers (Operon Technologies Inc., Almeda, CA, USA) OPL (11-20), OPM (01-20), OPN (01-20), OPQ (01-20), OPAZ (01-05) and OPBE (06-10) were used for PCR amplification. The PCR conditions for RAPD marker analysis reported by Demeke et al. (1996) were optimized for use with niger template DNA. Amplification reactions ( $25 \mu \mathrm{l}$ final volume) contained 50 ng of genomic DNA, $0.5 \mu \mathrm{M} 10$-mer primer, $10 \mathrm{mM}$ Tris$\mathrm{HCl} \mathrm{pH}$ 9.0, $150 \mathrm{mM} \mathrm{KCl,} 2.5 \mathrm{mM} \mathrm{MgCl} 2,250 \mu \mathrm{M}$ dNTPs and 0.5 units Taq polymerase. Amplification was performed in a programmable thermocycler (ModelPTC100: MJ research Inc., Waltham MA, USA) with 35 cycles of $95^{\circ} \mathrm{C}$ for $45 \mathrm{sec}, 37^{\circ} \mathrm{C}$ for $1 \mathrm{~min}$, and $72^{\circ} \mathrm{C}$ for 2 min with an initial denaturation of $94^{\circ} \mathrm{C}$ for $5 \mathrm{~min}$ and a final extension at $72^{\circ} \mathrm{C}$ for $15 \mathrm{~min}$.

\section{DNA electrophoresis}

The amplified products were separated electrophoretically in a $1.5 \%(\mathrm{w} / \mathrm{v})$ agarose gel containing $0.5 \mu \mathrm{g} \mathrm{ml}^{-1}$ ethidium bromide in $45 \mathrm{mM}$ Tris-borate, $1 \mathrm{mM}$ EDTA buffer, $\mathrm{pH}$ 8.0. Each lane was loaded with $25 \mu$ l loading dye [40\% $(\mathrm{w} / \mathrm{v})$ sucrose and $0.25 \%(\mathrm{w} / \mathrm{v})$ bromophenol blue]. Electrophoresis was carried out at $45-80 \mathrm{~V}$ for $3 \mathrm{hrs}$, and gels were viewed and photographed on UV transilluminator.

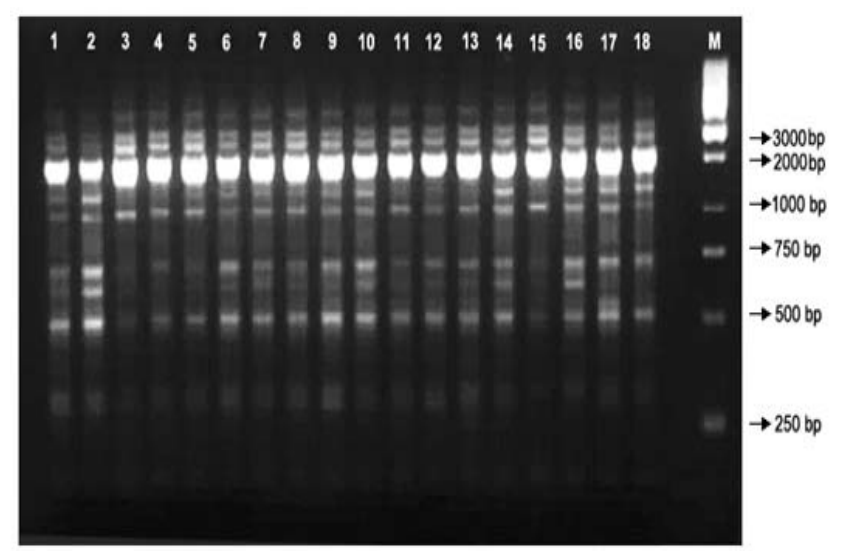

Figure 1. Lanes 1 to 18 represent RAPD profiles of leaf DNA from 18 niger cultivars (Table 1) using primer OPM-6 (Table 2) Lane M, 1 kbp DNA ladder. 


\section{Data analysis}

PCR amplification profiles of the eighteen niger genotypes for each primer were scored by visual observation. The presence of amplified bands at each position was recorded as one and its absence as zero. From these data, a SquaredEuclidean distance matrix was calculated to estimate pair-wise differences in the amplification products for all genotypes (Sokal and Sneath, 1973). Cluster analysis was done using a minimal variance algorithm (Ward, 1963) to construct a dendrogram. Furthermore, a Principal Component Analysis (PCA) was done to estimate relationship between cultivars.

\section{RESULTS AND DISCUSSION}

Preliminary experiments of RAPD reproducibility were carried out to determine the best concentration of the DNA to obtain the optimum number of bands. Varying concentration of template DNA (25-75 ng) revealed that $50 \mathrm{ng}$ allowed the maximum number of reproducible bands, and therefore $50 \mathrm{ng}$ was used in all subsequent PCR reactions.

Out of eighty Operon primers checked, 63 did not produce polymorphic bands or did not amplify clear products.

\section{Table 1. Details of seventeen selected 10 -mer primers and corresponding numbers of RAPD DNA markers (polymorphic and monomorphic) generated.}

\begin{tabular}{|c|c|c|c|c|c|}
\hline Code & Primer & Total & Polymorphic & Monomorphic & Percentage \\
\hline 1 & OPL-12 & 9 & 3 & 6 & 33.3 \\
\hline 2 & OPL-13 & 7 & 4 & 3 & 57.1 \\
\hline 3 & OPL-19 & 9 & 1 & 8 & 11.1 \\
\hline 4 & OPM-4 & 7 & 3 & 4 & 42.8 \\
\hline 5 & OPM-7 & 7 & 4 & 3 & 57.1 \\
\hline 6 & OPM- & 7 & 6 & 1 & 85.7 \\
\hline 7 & OPM- & 4 & 1 & 3 & 25.0 \\
\hline 8 & OPM- & 10 & 3 & 7 & 30.0 \\
\hline 9 & OPN-4 & 7 & 4 & 3 & 57.1 \\
\hline 10 & OPN- & 9 & 3 & 6 & 33.3 \\
\hline 11 & OPN- & 8 & 2 & 6 & 25.0 \\
\hline 12 & OPN- & 8 & 3 & 5 & 37.5 \\
\hline 13 & OPQ-1 & 3 & 1 & 2 & 33.3 \\
\hline 14 & OPQ-6 & 2 & 1 & 1 & 50.0 \\
\hline 15 & OPQ- & 9 & 2 & 7 & 22.2 \\
\hline 16 & OPAZ- & 6 & 3 & 3 & 50.0 \\
\hline 17 & OPBE- & 12 & 6 & 6 & 50.0 \\
\hline
\end{tabular}

Therefore, the 17 primers which produced good and reproducible polymorphic bands were used for further analysis of the 18 niger genotypes. The details of the primers producing polymorphic bands are presented in Table 1 . These 17 primers produced 124 DNA fragments in total; among them 74 fragment were monomorphic and 50 DNA fragments showed polymorphism in one or more genotypes (Figure 1 and Table 1). The total number of bands per primer ranged from 2 (OPQ1) to 12 (OPBE-9), with an average of 7.29 band per primer. The highest number (6) of polymorphisms was observed with primers OPM-10 and OPBE-9. The average number of polymorphic bands per primer was 2.94 and the percentage of polymorphic bands ranged from $11.1 \%$ (OPL-19) to $85.7 \%$ (OPM-10) with a mean value of $41.20 \%$. The SquaredEuclidean distances between pairs of accessions ranged from 2 to 31 . The frequency distribution showed that $86.91 \%$ of the distance values ranged from 13-25 (Figure 2). The minimum distance was between cultivars JNC-6 and N-48, while the maximum distances were between cultivars 'IGP-76' and 'JN30'. The high percentage of polymorphism for varieties tested suggests the existence of high genetic polymorphism in Indian niger cultivars. Similarly high polymorphisms (97\%) were reported among the 70 niger populations collected from different regions of Ethiopia (Geleta et al. 2007). Ethiopia is the center of origin and diversity of niger (Zeven and DeWet, 1982; Hiremath and Murthy, 1988), where it has been under cultivation for much longer than in any other places (Baagoe, 1974; Hiremath and Murthy, 1988). India is considered a secondary center of diversity (Baagoe, 1974; Hiremath and Murthy, 1988; Murthy et al. 1993), therefore, niger populations from Ethiopia should show higher genetic diversity than Indian cultivars.

The niger germplasm in India was collected after 1973 from the states of Madhya Pradesh, Orissa, Bihar, Andhra Pradesh and Karnataka which represent the major niger-growing states. The collections represent landraces and selected breeding lines (Getinet and Sharma, 1996).

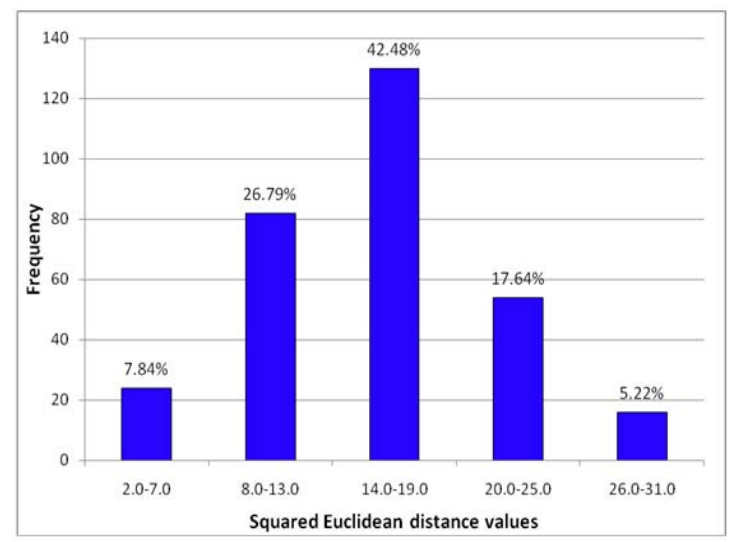

Figure 2. Frequency distribution of Squared Euclidean distance values obtained from pair-wise comparisons between the 18 niger cultivars selected. The vertical axis indicate the number of pair-wise comparisons; values on the bar indicate the percentage of pair-wise Euclidian distance values falling in the frequency classes indicted on the horizontal axis. 
The highest morpho-physiological variability was noticed in central and eastern peninsular areas. For example, some genotypes from Orissa possess big seeds, compared with the medium seed types of Karnataka, which have higher oil content (e.g. 40-43\%; Getinet and Sharma, 1996). Coldadaptable germplasm also occurs in the eastern hills, especially in Sikkim, while drought-tolerant germplasm occurs in central peninsular regions of India (Getinet and Sharma, 1996).

In the present study variation between niger cultivars was observed with 17 selected primers: the relevant number of primers utilised is crucial for valid conclusions, owing to problems associated with the reproducibility in RAPD technology (Kumar, 1999). On the other hand, the pedigree background and the geographical distribution of the 18 niger cultivars influence the RAPD variation between closely related cultivars.

The dendrogram based on RAPD analysis is shown in Figure 3. All cultivars grouped in two major clusters. The first cluster comprised 6 early maturing cultivars (e.g. N129 and N134; 80-90 days). The second cluster consisted of 12 cultivars, mostly late maturing (e.g. GA-8 and GA-9; 135-145 days), with two major sub-groups of eight and four cultivars. The cultivar No-71, which is early maturing, nevertheless was in this second cluster. IGP-76, the National Check for yield characteristics, as well as the cultivars ONS-124, IGPN-9628, and JNC-2, which are also high yielding cultivars, were all included in the same cluster. The division between early maturing and late maturing cultivars detected by cluster analysis was confirmed also by PCA (Figure 4).

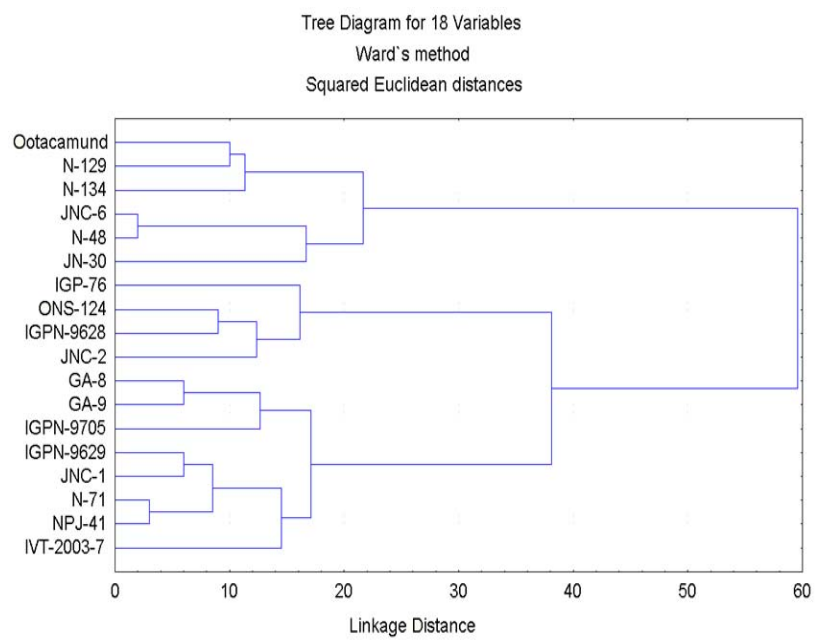

Figure 3. Dendrogram showing genetic variability relationships between 18 niger cultivars. The Squared-Euclidean distance (horizontal axis) between objects is used as the distance measure; the clustering was performed following the method of Ward (1963).

Systematic efforts were made to analyze variability among land races and germplasm existing in India after 1994; among the traits studied were days to $50 \%$ flowering, days to $50 \%$ maturity, plant height, number of capitulae per plant, number of branches per plant, seed yield,

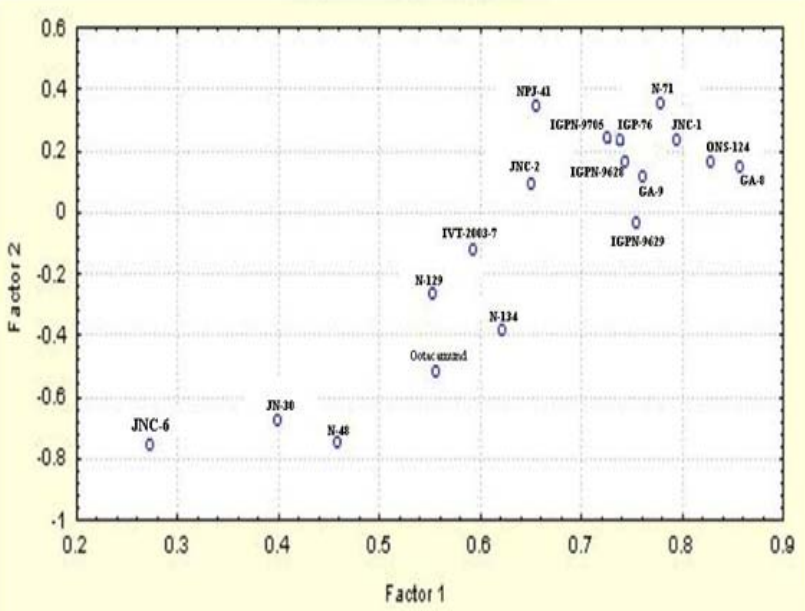

Figure 4. PCA of RAPD-generated DNA markers for 18 niger cultivars.

oil content and protein content (Getinet and Sharma, 1996). However, the variability for these characteristics is not discrete since niger is a highly out-crossing species and this behaviour poses major problems for the crop improvement. The diverse agro-climatic conditions of India, furthermore, influence variability. That is why environmental-neutral biochemical and molecular markers such as RAPD are very useful for breeders working with continuous variation (Kumar, 1999).

The moderated to high degree of RAPD polymorphism observed in the present material (the 17 primers generated one or more polymorphic markers, and frequency of polymorphic marker was as high as $85.7 \%$ ) suggest that RAPD can efficiently be used in cultivar identification of niger, as observed already in crops like tomato (Noli et al. 1999), pepper (Prince et al. 1995), etc. Therefore, niger breeding programs based on selection and hybridization will benefit from the data and the patterns reported in this study.

\section{REFERENCES}

BAAGOE, J. The genus Guizotia (Compositae): a taxonomic revision. Botanisk Tidsskrift, 1974, vol. 69, p. 1-39.

DEMEKE, T.; LYNCH, D.R.; KAWCHUK, L.M.; KOZUB, G.C. and ARMSTRONG, J.D. Genetic diversity of potato determined by random amplified polymorphic DNA analysis. Plant Cell Reports, May 1996, vol. 15, no. 9, p. 662-887.

DUTTA, Paresch Chandra; HELMERSSON, Seved; KEBEDU, Eshetu; ALEMA, Getinet and APPELQVIST, LarsÃke. Variation in lipid composition of niger seed (Guizotia abyssinica Cass) samples collected from different regions in Ethiopia. Journal of the American Oil Chemists Society, August 1994, vol. 71, no. 8, p. 839-843.

GELETA, Mulatu; BRYNGELSSON, Tomas; BEKELE, Endashaw and DAGNE, Kifle. Genetic diversity of 
Guizotia abyssinica (L. f.) Cass. (Asteraceae) from Ethiopia as revealed by random amplified polymorphic DNA (RAPD). Genetic Resources and Crop Evolution, May 2007, vol. 54, no. 3, p. 601-614.

GETINET, A. and SHARMA, S.M. Niger [Guizotia abyssinica (L. f.) Cass.] Promoting the conservation and use of underutilized and neglected crops.5. International Plant Genetic Resources Institute, Rome, 1996, 59 p. ISBN 92-9043-292-6.

HIREMATH, S.C. and MURTHY, H.N. Domestication of niger (Guizotia abyssinica). Euphytica, April 1988, vol. 37, no. 3, p. 225-228.

HOREJSI, Thomas and STAUB, Jack E. Genetic variation in cucumber (Cucumis sativus L.) as assessed by random amplified polymorphic DNA1. Genetic Resources and Crop Evolution, August 1999, vol. 46, no. 4, p. 337-350.

KUMAR, Lalitha Sunil. DNA markers in plant improvement - Chromosome organization and evolution in a disomic polyploid. Biotechnology Advances, September 1999, vol. 17, no. 2-3, p. 143-182.

MURTHY, H.N.; HIREMATH, S.C. and SALIMATH, S.S. Origin, evolution and genome differentiation in Guizotia abyssinica and its wild species. Theoretical and Applied Genetics, December 1993, vol. 87, no. 5, p. 587-592.

NOLI, E.; CONTI, S.; MACCAFERRI, M. and SANGUINETI, M.C. Molecular characterization of tomato cultivars. Seed Science and Technology, April 1999, vol. 27, no. 1, p. 1-10.

NYBOM, Hilde. Comparison of different nuclear DNA markers for estimating intraspecific genetic diversity in plants. Molecular Ecology, May 2004, vol. 13, no. 5, p. 1143-1155.

PRADHAN, K.; MISHRA, R.C. and PAIKARY, R.K. Genetic variability and character association in niger. Indian Journal of Genetics and Plant Breeding, 1995, vol. 55 , p. 457-459.

PRINCE, J.P.; LACKNEY, V.K.; ANGELES, C.; BLAUTH, J.R. and KYLE, M.M. A survey of DNA polymorphism within the genus Capsicum and the fingerprinting of pepper cultivars. Genome, April 1995, vol. 38, no. 2, p. 224-231.

SOKAL, R.R. and SNEATH, P.H.A. Principles of Numerical Taxonomy. W.H. Freeman and Company, San Francisco, 1973. 359 p.
WARD, Joe H. Hierarchical grouping to optimize an objective function. Journal of the American Statistical Association, March 1963, vol. 58, no. 301, p. 236-244.

ZEVEN, A.C. and DEWET, J.M.J. Dictionary of cultivated plants and their regions of diversity: excluding most ornaments, forest trees and lower plants. Center for Agriculture Publication and Documentation, Wageningen, 1982. 263 p. 